\title{
Use of Blog to Improve English Writing in the Chinese Tertiary EFL Classrooms
}

\author{
SHEN Qi-yuan ${ }^{1}$ \\ ${ }^{1}$ School of Foreign Languages, Jiangxi Normal University, China \\ Correspondence: SHEN Qi-yuan, School of Foreign Languages, Yaohu Campus, Jiangxi Normal University, \\ Nanchang, 330022, China. E-mail: liyingxiao@yahoo.com
}

Received: June 29, 2013 Accepted: July 31, 2013 Online Published: September 4, 2013

doi:10.5539/elt.v6n10p51 URL: http://dx.doi.org/10.5539/elt.v6n10p51

\begin{abstract}
According to the constructivism learning theory, blog may act as a useful tool for improving writing capability. For this purpose, the present article attempts to explore the potential of blog for improving English writing in the Chinese tertiary EFL classrooms. A quasi-experimental study was conducted in a Chinese university to compare the effects between traditional in-class process-oriented writing instruction and blog integrated writing instruction. Result of the experiment shows that blog integrated writing instruction resulted in better writing performance. Therefore, the claim that blog may promote more effective writing instruction is substantiated.
\end{abstract}

Keywords: blog, English writing, the Chinese EFL tertiary classrooms

\section{Introduction}

Writing has always been an important aspect in the Chinese EFL classrooms. However, many Chinese students find writing difficult because the English writing system is so different from that of their mother tongue. With the development of internet technology, blog has provided a great potential to facilitate English writing, especially for the Chinese students who lack sufficient exposure to the authentic English language. According to the College English Curriculum Requirement, which was formulated by the Chinese Ministry of Education in 2004, we should promote computer and internet based English teaching in the Chinese tertiary classrooms. For this reason, the present article explored the effect of blog on the students' writing performance in the Chinese tertiary classrooms.

\section{Theoretical Basis}

According to the constructivism learning theory (Kliebard, H, 1992), it is on the basis of their experiences that people produce knowledge and form meaning. Within the constructivism learning theory, accommodation and assimilation are the two key concepts which create the construction of an individual's new knowledge. Assimilating causes an individual to incorporate new experiences into the old experiences, which in turn causes the individual to develop new outlooks, rethink what were once misunderstandings, and evaluate what is important, ultimately altering their perceptions. On the other hand, accommodation is reframing the world and new experiences into the mental capacity already present.

Since the 1990s, constructivism has brought about a pedagogical revolution worldwide, which inevitably accelerated the research of second language acquisition. Guided by the principles of behaviorism and cognitivism, constructivism has developed such teaching models as Scaffolding Instruction, Anchored Instruction and Random Access Instruction. All these models emphasize the importance of situation creation, team work and autonomous study. Learning is considered to be a repeated process of structuring, by which learners actively build their knowledge on their own or with the help of others. Learning is also an active process by which learners construct new ideas on the basis of their present and previous knowledge (Bruner, 1990). Constructivism established the students' central place in the instructional activities, allowing them to acquire the target language by way of learning in contexts jointly created by the teachers and the students. Thus the learning activities are more purposeful, authentic and cooperative. According to the constructivism learning theory, blog may act as a useful tool to improve the students' writing performance in the Chinese tertiary EFL classrooms because the students in this learning environment are effective thinkers and meaning builders while the teachers are helpers and facilitators. 


\section{Blog Writing Process}

College English writing reform in China aims at providing a platform in which the students can improve their writing performance step by step whereas they are also able to examine their progress in the meantime. Undoubtedly, internet technology has helped create such a platform which is called blog. In a sense, we can say that blog has revolutionized traditional writing instruction. Firstly, it promotes personalized learning and autonomous learning. Secondly, it advocates a transformation of the role of the teacher from instructors to facilitators. Thirdly, as we all know, writing consists of a series of segments such as topic choice, material selection and plot planning etc. By way of blog, the students can write their articles and the teachers can evaluate the articles online, which maximizes the interaction between them. Therefore, blog makes it possible to link the segments of writing together cyclically in a nonlinear way (see Figure 1). What's more, this online interaction ensures immediate evaluation of a piece of writing.

From figure 1, we can see that blog writing is made up of three steps and each step comprises two functions. They are as follows: writing-recording, thinking-enjoying, evaluation-learning. Obviously, this writing process embodies the principles of autonomous learning advocated by the constructivism learning theory. A college writing model can be built upon this blog writing process, which can enhance the monitoring of the writing process and put autonomous writing into practice.

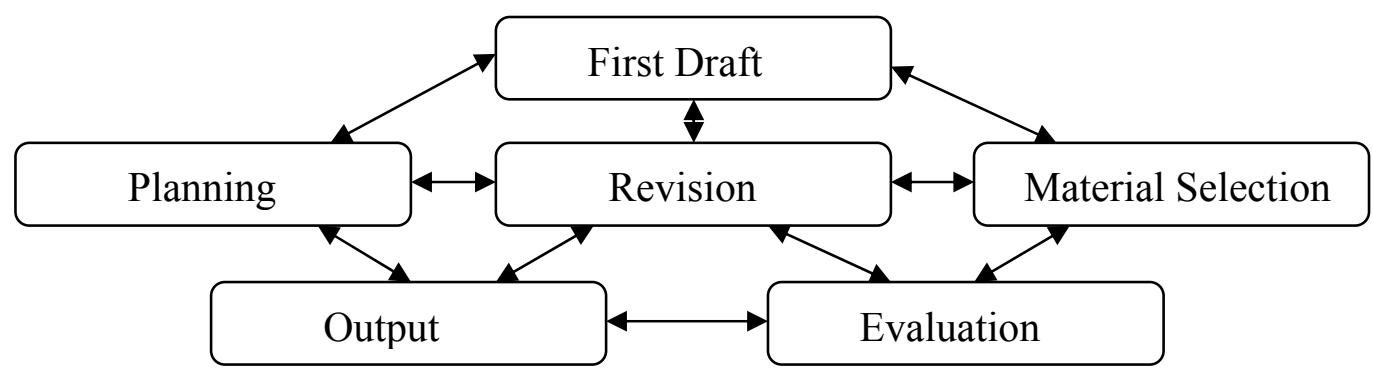

Figure 1. Blog writing process

\section{Blog-Integrated Writing Instruction}

Blog-integrated writing instruction consists of three stages, that is, preparation, writing and revision (see Figure 2). We will study the three stages in detail.

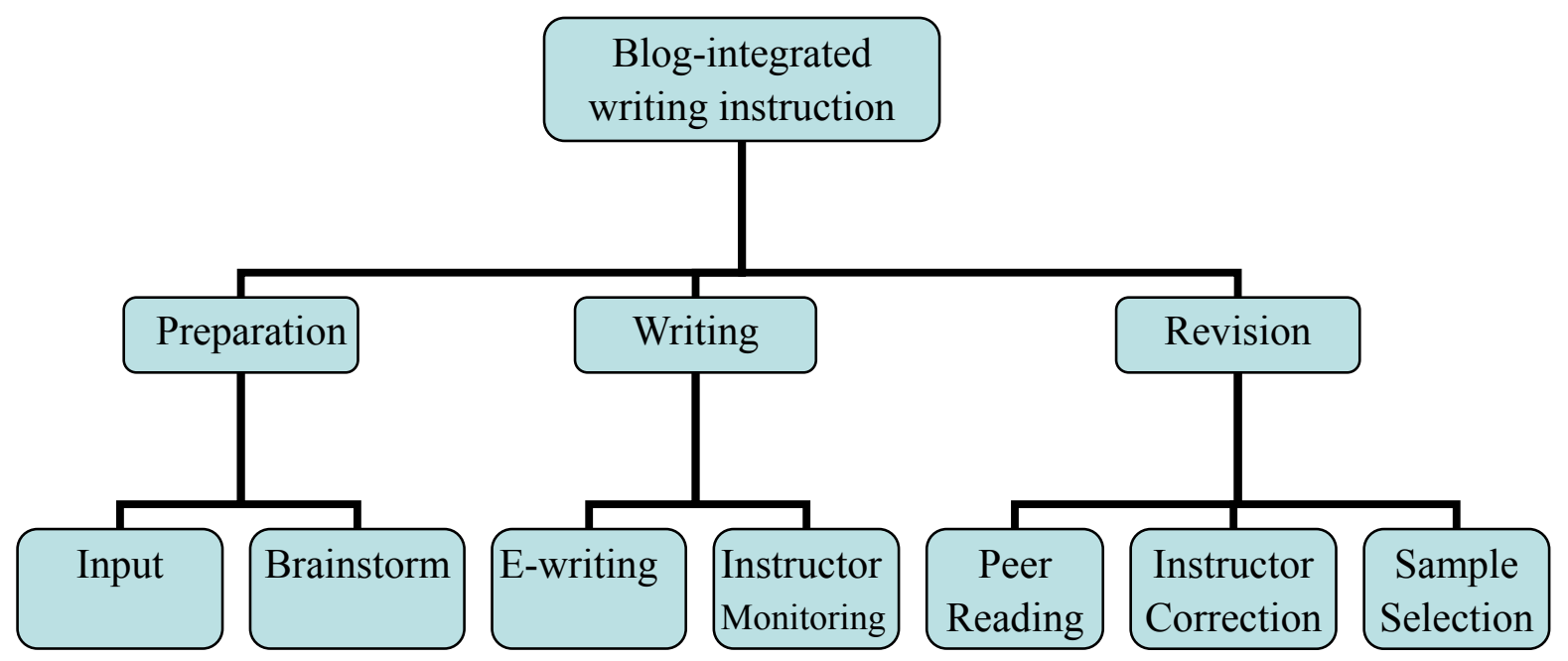

Figure 2. Blog-integrated writing instruction

\subsection{Preparation}

At this stage, a teacher provides a theme or scene according to which students choose a topic and organize their thoughts on their own. The students should collect as many writing materials as possible by logging onto the websites. What's more, they can discuss the related issues by online interaction, which can easily stimulate each other's imagination. Online evaluation among themselves can also help form their writing plot. 
By putting various links of learning resources onto blog, a teacher can expose students to the target language, which aids to broaden the students' horizon and enhance their language sense. Besides, the students are able to use the resources to search the writing materials and determine their topics. One advantage of blog is that it takes into consideration the students' individual differences, which makes it possible for them to pick up the materials according to their own needs. After receiving sufficient input and accumulating enough writing materials, the students can start their writing without much effort.

Brainstorming is a good way of generating ideas for writing. In this process, students can suspend any concern about staying organized. The goal is to pour their thoughts out without worrying about whether they make sense or how they fit together. Because students have different learning styles, some students will be uncomfortable with the disorganized frenzy of spilling thoughts out. Due to its nature of instant writing and correction, blog can help them leap out of the mire because they can change what has been written down immediately once mismatches occur.

\subsection{Writing}

Having chosen the topic and accumulated sufficient materials, the students can begin their writing tasks. Blog's e-writing mode provides the students with great conveniences by which they can edit their writings effortlessly. In addition, online dictionary gives the students easy access to the English words and phrases they need to construct their works.

The teacher should monitor the whole writing stage and help to correct any error committed by the students. RSS technology is a good tool that can be used to fulfill this job. By utilizing RSS software, the teacher can keep up with the students' development and give them feedback without necessarily logging onto their blogs. Besides, the students can be divided into different groups and review each other's writing. After receiving the feedback, the students can check whether their writings make sense and whether structural or grammatical mistakes exist. The students' writings on blog are sequenced in chronological order. Thus the teacher can examine the writings and feedbacks without much difficulty, which greatly facilitates the monitoring work.

\subsection{Revision}

Revision is the prerequisite for producing a piece of good writing and forms an integral part of writing ability. The revision stage in blog-integrated writing instruction is an open process within a feedback system. In this process, the students' writings approach perfection gradually with the help of teacher-student interaction and student-student interaction.

Blog blurs the boundaries between an author and his readership, which greatly increases peer exchange reading and peer exchange evaluation, both of which are indispensable resources for effective input. The e-writing pattern of blog makes it much more convenient for the students to read and evaluate each other's writings. By way of reading and evaluating a peer's writing, the students can learn a lot about writing skills from each other. In the meantime, aware of the presence of their readership, they carry out their writing tasks with more enthusiasm and responsibility and pay more attention to wording and grammaticality. Therefore, the collaboration between the students' individual work and their team work not only trains the students' autonomous learning ability but also reduces the teacher's grading workload.

Teacher's correction still plays an important role in helping the students to avoid making mistakes and to improve their writing ability. Blog's e-writing mode is able to correct such basic errors as spelling, grammar, punctuation and format in a piece of writing automatically. Thus the teacher can put his emphasis on the writing's content, structure and organization. For the common mistakes, the teacher should explain them in class; for a particular mistake, it is better for him to communicate with the relevant student via blog. The students can express their doubts about the teacher's evaluation and the teacher can further clarify his intentions. In this way, learning is no longer cramming but equal and mutual communication. Teacher is no longer a judge of language use but a reader and a guider. This learning environment greatly enhances the students' self-awareness and self-confidence.

Masterpieces should be selected from among the students' writings and be published on blog because it gives all the students an opportunity to appreciate the good qualities of a piece of writing. The authors of the masterpieces are surely proud of their success and full of sense of fulfillment. What's more, for those who have made progress, their writings should also be published on blog as an encouragement and praise. The highlights of these writings should be pointed out and explained. Therefore, blog serves as a platform for showing achievement as well as a platform for displaying progress.

In conclusion, guided by the constructivism learning theory, blog-integrated writing instruction is a cyclical process of interaction with teachers being the facilitator and organizer and students being the active learning 
agent. During this process, attention is focused on how to improve writing capability instead of on how to mark a piece of writing, which is distinct from the traditional way of writing instruction in a Chinese tertiary class. For this reason, empirical research was carried out to test the effectiveness of this teaching method.

\section{Empirical Study}

The study compared the results of blog-integrated writing instruction with those of the traditional in-class process-oriented writing instruction. It lasted one semester (from September 2012 to January 2013). SPSS 11.5 statistics software was used to analyze the pre-test and post-test results of the control group and the experimental group respectively. The analytical results were supposed to show the different effects of the two writing instruction methods.

\subsection{Subjects}

Two classes from Jiangxi Normal University were selected as subjects. Class One Grade 2011 of the Chinese department was the experimental group and Class Two Grade 2011 of the Chinese department was the control group. Each group consisted of 50 students. Technically speaking, the research was a quasi-experiment because two intact classes were used as subjects.

\subsection{Instrument}

Two instruments were used in the experiment. The first one made use of the College English Band 4 composition marking system, according to which a piece of writing is measured in terms of purpose, reasoning, content, organization and expression. Every piece of writing of the two groups' pre-test and post-test was graded according to this system in terms of the five standards. Then SPSS was used to analyze the results. The second instrument was a questionnaire at the end of the experiment.

\subsection{Procedure}

Before the experiment, a pre-test was conducted to gather information about the two groups' writing capability. The test lasted 30 minutes. The title was College Life. At the end of the experiment, a post-test was carried out. This test also lasted 30 minutes. The title was My Dream. The total score of the two tests was the same, that is, 15. Besides, a questionnaire was conducted to collect feedback about blog-integrated writing instruction from the control group.

\subsection{Data Analysis}

\subsubsection{T-Test Analysis}

From table 1, we can see that the average score of the experimental group had risen from 7.97 to 8.78 whereas that of the control group had risen from 8.03 to 8.52 . The statistics show that the two groups had made progress after one semester's writing instruction. Use SPSS 11.5 software's t-test function, we obtained the respective p-value of the two groups' pre-test and post-test. The experimental group's p-value was 0.01 , which signifies that the means are obviously different at the significance level. The control group's p-value was 0.12 , which suggests that the means are not different. In other words, the experimental group had made more marked progress than the control group. It means that blog-integrated writing instruction proved to be a more effective way of writing instruction in the Chinese tertiary EFL classrooms.

Table 1. The pre-tests and post-tests of the experimental group and the control group

\begin{tabular}{lccccc}
\hline Group & & $\mathrm{M}$ & $\mathrm{SD}$ & $t$ & $p$ \\
\hline \multirow{2}{*}{ Experimental Group } & Pre-test & 7.97 & 1.28 & & -2.12 \\
& & & & & 0.01 \\
& Post-test & 8.78 & 1.54 & & \\
Control Group & Pre-test & 8.03 & 1.10 & & 0.12 \\
& & & & -1.38 & \\
\hline
\end{tabular}

\subsubsection{Questionnaire Analysis}

All the members of the experimental group completed a questionnaire at the end of the experiment. All the 
answers were valid. The questionnaire and its analysis are shown at Table 2. According to the questionnaire, $83.4 \%$ of the students held positive attitude toward blog-integrated writing instruction; 92.3 of them favored online grading and evaluation; 88.7 of them were ready to use the blog writing model; $90.3 \%$ of them considered blog writing as a good way to improve their writing ability.

Table 2. A questionnaire of the control group

\begin{tabular}{|c|c|c|c|}
\hline \multirow{3}{*}{$\begin{array}{l}\text { Question } \\
\text { 1. What do you think of blog-integrated writing } \\
\text { instruction? }\end{array}$} & \multicolumn{3}{|c|}{ Answer analysis } \\
\hline & Bad & Average & Good \\
\hline & $5.40 \%$ & $11.20 \%$ & $83.40 \%$ \\
\hline \multirow{2}{*}{$\begin{array}{l}\text { 2. Comparing with traditional methods, what is the } \\
\text { effect of blog-integrated writing instruction? }\end{array}$} & $\mathrm{Bad}$ & Average & Good \\
\hline & $2.50 \%$ & $13.70 \%$ & $83.80 \%$ \\
\hline \multirow{2}{*}{$\begin{array}{l}\text { 3. Do you agree with teacher's online grading and } \\
\text { evaluation? }\end{array}$} & No & Average & Yes \\
\hline & $1.20 \%$ & $6.50 \%$ & $92.30 \%$ \\
\hline \multirow{2}{*}{ 4. Are you glad to use this writing method? } & No & Glad & Very Glad \\
\hline & $1.90 \%$ & $10.40 \%$ & $88.70 \%$ \\
\hline \multirow{2}{*}{$\begin{array}{l}\text { 5. Do you think blog-integrated writing instruction } \\
\text { helps to improve your writing ability? }\end{array}$} & No & A lot & Greatly \\
\hline & $8.70 \%$ & $46.80 \%$ & $44.50 \%$ \\
\hline
\end{tabular}

\section{Discussion}

Since the adoption of blog-integrated writing instruction, both teacher and students have benefited a lot from online interaction. More and more students browse blog with much higher frequency than ever before. Almost all the students are willing to display their writings on blog. What's more, they are always ready to ask for help from others and give their suggestions about teaching via blog. As a new type of writing instruction, blog has won its support from the majority of the students.

The experimental results show that blog-integrated writing instruction can effectively improve students' writing performance. The reasons are as follows. Firstly, when acting as a writing platform, blog can be a functional tool of cyclical writing process, teamwork and online immediate evaluation and correction. Secondly, peer pressure in an online environment pushes the students into focusing more attention on their writing performance. Thirdly, evaluation is integrated into teaching in the dynamic online writing process, which brings the students' subjective initiative into full play.

Internet is full of great information and resources to help the students get started. However, they may sometimes be overwhelmed by the large amount of information so as not to be able to choose the appropriate materials needed for their writing (Hayes \& Flower, 1986). Under such circumstances, the teacher should help them to make correct choices and take actions to train them to identify the relevant information.

Due to the cultural differences, the Chinese people have different ways of thinking and expressing their ideas from the English speaking people. Such differences have an impact on language usage. For instance, the Chinese people are good at summary descriptions whereas the English speaking people are adept at argument demonstrations. For this reason, much effort should be made to pinpoint the differences between the two languages in terms of diction, syntax and paragraphing. Everything possible should be done to avoid the negative transfer of the mother tongue so that the students can perform their writing tasks in an idiomatic way.

Such factors as blog's openness, students' lack of self-discipline and large-sized class may make it difficult for a teacher to manage and monitor his teaching activities efficiently. Blog-integrated writing instruction is a kind of autonomous learning under instructors' guidance, not a laissez-faire autonomous learning. Therefore, much research should be done to tackle the issue as to how to lead the students to continue their blog-integrated writing activities persistently.

\section{Conclusion}

By definition, blog-integrated writing instruction is created by integrating blog into the various segments of the whole writing process. The "trigger function" of blog greatly increases the students' linguistic output as well as their teamwork. The students can avail themselves of the vast amount of resources supplied by internet and 
select what is needed to get along with their writing tasks. What's more, the students are greatly motivated by the comprehensive dynamic evaluation system on blog.

Compared with the traditional in-class writing instruction model, the empirical study shows that blog-integrated writing instruction helps to improve the students' writing skills more efficiently in terms of syntax, expression and coherence. The present study has found out the connection point between blog technology and college English writing instruction, on the basis of which blog can be effectively integrated into the traditional college writing instruction classes. This integration results in better teaching effects and better writing skills. However, the study detailed in this article is still at the exploratory stage. Further research still needs to be done to improve blog-integrated writing instruction in the Chinese tertiary EFL classrooms.

\section{References}

Bruner, J. (1990). Acts and Meaning. Cambridge, MA: Harvard University Press.

Campbell, A. P. (2003). Weblogs for Use with ESL Classes. The Internet TESL Journal.

Campbell, A. P. (2004). Using Live Journal for Authentic Communication in EFL Classes. The Internet TESL Journal, 10(9).

Dieu, B. (2004). Blogs for Language Learning. Essential Teacher, 1, 26-30.

Eastman, D. (2005). Blogging. English Language Teaching Journal, 59(4).

Hayes, J. R., \& Flower, L. S. (1986). Writing research and the writer. American Psychologist, 41.

Kliebard, H. (1992). Constructing a history of American curriculum in Handbook of research on curriculum (pp. 157-184).

Johnson, A. (2004). Creating a Writing Course Utilizing Class and Student Blogs. The Internet TESL Journal, $10(8)$.

\section{Copyrights}

Copyright for this article is retained by the author(s), with first publication rights granted to the journal.

This is an open-access article distributed under the terms and conditions of the Creative Commons Attribution license (http://creativecommons.org/licenses/by/3.0/). 